\title{
MONOGRÁFICO I
}

\section{NIETZSCHE COMO PENSADOR POLÍTICO}

\author{
Coordinado por
}

Diego Sánchez Meca (UNED) 



\title{
"Una larga escala de jerarquía y diferencia de valor entre hombre y hombre" . Alcance y límites del agonismo político nietzscheano
}

\section{"A long scale of hierarchy and difference in value between man and man". Scope and Limits of Nietzschean Political Agonism}

\author{
Manuel Barrios Casares ${ }^{2}$ \\ Universidad de Sevilla (España) \\ ORCID: https://orcid.org/0000-0002-7311-2770
}

Recibido: 12-01-2021

Aceptado: 02-02-2021

\section{Resumen}

Tras repasar la fortuna histórica de Nietzsche como pensador político, se discute qué aspectos de su filosofía pueden resultar más provechosos para el despliegue de una democracia pluralista, en el sentido del agonismo político reivindicado hoy por algunos de sus intérpretes. Pero también se señalan los motivos por los que una articulación de democracia y cultura aristocrática queda coagulada en su filosofía. Para ello se aborda la cuestión del agón en Nietzsche y se señala su discrepancia con la idea schmittiana del par amigo-enemigo,

\footnotetext{
${ }^{1}$ JGB, 257. Las obras de Nietzsche se citan según la nomenclatura internacionalmente admitida, con las siglas y referencias de la edición crítica de Giorgi Colli y Mazzino Montinari. También nos remitimos a las ediciones en castellano de las Obras Completas (OC, volumen y página) y los Fragmentos Póstumos (FP, volumen y página), publicadas por la editorial Tecnos bajo la dirección de Diego Sánchez Meca.

2 (mbarrios@us.es). Catedrático de Filosofía de la Universidad de Sevilla. Miembro del equipo de investigación editor de los Fragmentos Póstumos y las Obras Completas de Nietzsche en castellano a través de sucesivos Proyectos Nacionales de I+D+i. Sobre Nietzsche ha publicado La voluntad de poder como amor (reed: Madrid, Arena Libros, 2006), Hölderlin y Nietzsche, dos paradigmas intempestivos de la modernidad en contacto (Reflexión/US, 1992); Narrar el abismo. Ensayos sobre Nietzsche, Hölderlin y la disolución del clasicismo (Pre-textos, 2001); Voluntad de lo trágico. El concepto nietzscheano de voluntad a partir de "El nacimiento de la tragedia" (Er, 1993; Biblioteca Nueva, 2002), Nietzsche y la curvatura de la Ilustración (Brujas, Argentina, 2019), Tentativas sobre Nietzsche (Madrid, Abada, 2019).
} 
como distintiva de la esencia de lo político, situando así en perspectiva la crítica nietzscheana de la modernidad.

Palabras-clave: Nietzsche, agonismo, pensamiento político, modernidad, metafísica.

\begin{abstract}
After reviewing the historical fortune of Nietzsche as a political thinker, it is discussed what aspects of his philosophy can be most useful for the deployment of a pluralist democracy, in the sense of political agonism claimed today by some of his interpreters. But the reasons why an articulation of democracy and aristocratic culture is coagulated in his philosophy are also pointed out. For this, the question of the agon in Nietzsche is approached and its discrepancy with the Schmittian idea of the friend-enemy pair, as distinctive of the essence of the political, is pointed out, thus placing the Nietzschean critique of modernity in perspective.
\end{abstract}

Key-words: Nietzsche, Agonism, Political Thought, Modernity, Metaphysics.

Con una insistencia que se iría agudizando cada vez más, hasta volverse casi obsesiva en algunos pasajes de sus últimos escritos, Nietzsche reclamaba como requisito hermenéutico indispensable para evitar previsibles malentendidos en torno a su obra la necesidad de practicar con ella "el arte de leer bien" (AC, 52), esto es, el arte de leer despacio, con paciencia, pericia y probidad filológicas, rumiando sus textos, atendiendo a los matices, captando las ironías, paradojas y demás juegos de sentido destilados por su escritura -en definitiva, sabiendo calibrar cuánto había en ella de desafío, de pose o enmascaramiento, de experimento con la verdad. La pregunta explícita de si se le había comprendido, enunciada hasta en tres ocasiones en los tres epígrafes finales de su Ecce Homo, no constituía una simple provocación al lector o un mero expediente retórico: delataba un temor real ante la posibilidad de ser malinterpretado y, con ello, al mismo tiempo, expresaba en otro registro esa singularísima consciencia suya de representar una fatalidad para la época, de ser un destino llamado a trastocar los cimientos de la cultura moderna: una consciencia que, en este caso, adoptaba la forma de funesto presagio de la confusión que de inmediato caería sobre su legado intelectual.

La dificultad de leer su obra como un todo, de recorrer en su integridad las múltiples vicisitudes e inflexiones de su itinerario intelectual-dificultad incluso 
material en un primer momento, debido a las manipulaciones de sus textos realizadas por su hermana y editora, Elisabeth Förster-Nietzsche- favoreció la mitificación de su ambigua figura, a caballo entre el intelectual puro y el artista genial, en el no menos ambiguo espacio de la Kulturkritik del cambio de siglo ${ }^{3}$. Se allanaba así el camino para la apropiación völkisch de sus ideas, anticipada en el Archivo Nietzsche de Weimar por la actitud militante de sus impulsores (Max y Richard Oehler, Oswald Spengler o la propia Elisabeth, entre otros) y en el círculo de Stefan George por la celebrada monografía de Ernst Bertram, Nietzsche, ensayo de una mitología (Berlín, 1918). En los años treinta, autores como Alfred Baeumler culminarían esta desfiguración ideológica, haciendo de Nietzsche el profeta de la nueva Alemania y de la nueva raza aria ${ }^{4}$. De poco sirvieron entonces sus pronunciamientos de madurez a favor de una Europa unida y en contra del nacionalismo, de la política de Bismarck o del "evangelio de cervecería" del filisteísmo cultural (GD-Deutsche-2) y del antisemitismo ${ }^{5}$. Quedaba consagrada así la línea de lectura más reaccionaria de aquello que el ensayista y crítico literario danés Georg Brandes había bautizado en 1888, en sus lecciones sobre el filósofo, como su "radicalismo aristocrático".

Con semejante lastre, la exégesis del pensamiento nietzscheano tuvo que remar a contracorriente desde fecha bien temprana, sin que ni siquiera la crítica más ecuánime y documentada pudiera librarse de la sospecha de estar condenando o exculpando a un autor maldito cuando dictaminaba acerca de sus concepciones filosóficas. Si en algún momento se hizo especialmente pertinente aquella cautela que Nietzsche pidió ante sus escritos, fue sin duda a la hora de calibrar la incidencia política de sus ideas. No era fácil controlar

\footnotetext{
3 Para las líneas fundamentales de esta historia de la recepción del pensamiento nietzscheano, vid. Richard F. Krummel, Nietzsche und der deutsche Geist. 4 vols. Berlín, Walter de Gruyter, 1974; Steven Aschheim, The Nietzsche Legacy in Germany, 1890-1990. Berkeley, University of California Press, 1992; Christopher E. Forth, Zarathustra in Paris. The Nietzsche Vogue in France, 1891-1918. DeKalb: Northern Illinois University Press, 2001.

${ }^{4}$ A. Baeumler, Nietzsche der Philosoph und der Politiker, Leipzig, Reclam, 1931.

${ }^{5}$ La crítica a las principales figuras del movimiento antisemita de su época es frecuente en los textos de Nietzsche. Muchos de estos pronunciamientos, en especial los de su correspondencia, fueron silenciados por su hermana y por Oehler. Vid. como muestra esta carta de Nietzsche a su editor, el antisemita Fritsch, del 29 de marzo de 1887, que su hermana declaro perdida: "Por la presente le devuelvo los tres números que me remitió de su Correspondencia [antisemita], agradecido por la confianza de permitirme echar un vistazo a la confusión de principios subyacente a este extraño movimiento. Pero le pido que en el futuro se abstenga de estos envíos: pues temo perder mi paciencia. Créame: ese deseo repugnante de diletantes aburridos de opinar acerca del valor de los hombres y de las razas, esa sumisión a 'autoridades' (por ejemplo, E. Dühring, R. Wagner, Ebrard, Wahrmund, P. de Lagarde - ¿quién de ellos es el más injustificado, el más injusto en cuestiones de moralidad e historia?) que todo espíritu sensato rechazaría con frío desprecio, esas constantes y absurdas falsificaciones y esas componendas de vagos conceptos como 'germano', 'semita', 'ario', 'cristiano', 'alemán'- todo eso podría a la larga irritarme seriamente y sacarme de la irónica benevolencia con la que hasta ahora he contemplado las virtuosas veleidades y fariseísmos de los alemanes de hoy día. En definitiva: ¿cómo cree que me siento cuando los antisemitas ponen en su boca el nombre de Zaratustra?" (BVN-1887, 823).

${ }^{6}$ Georg Brandes, "Aristokratischer Radikalismus. Eine Abhandlung über Friedrich Nietzsche", en Deutsche Rundschau 63 (1890), pp. 52-89.
} 
el efecto fascinante del difuso nietzscheanismo que desde muy pronto se había extendido entre los grupos más dispares -anarquistas, socialistas, nihilistas, socialdarwinistas, judíos y antisemitas, cristianos liberales y ateos radicalesatraídos por la rotundidad de sus proclamas. En los literatos y artistas de las más diversas corrientes de vanguardia fue donde su huella caló más hondo, prolongando su estela a lo largo de toda la primera mitad del siglo veinte a través de nombres como los de Hofmannsthal, Gide, Strindberg, Rilke, Broch, Musil, Thomas Mann, Hermann Hesse, Stefan Zweig, Gottfried Benn o Ernst Jünger. Para todos ellos, con su diagnóstico del nihilismo como enfermedad de la cultura occidental, Nietzsche había sido el primero en divisar esa crisis de los valores cristiano-burgueses y esa colisión de la conciencia moderna europea que acompañaba al convencimiento finisecular de que el sentido unitario de la existencia se había quebrado de forma irreparable. La vivencia de pérdida de una totalidad armónica de la vida, de enrarecimiento del lenguaje y descomposición de la identidad del yo, la sensación de falta de paradero y de oscurecimiento de la razón, habían sido tematizadas por Nietzsche con tanto mayor poder de sugestión cuanto que él mismo se había tomado como caso ejemplar y registrado en su propia obra las consecuencias, formales y de contenido, de semejante extravío mediante la renuncia a toda construcción sistemática y el empleo de una escritura aforística, cargada de rupturas semánticas, de contradicciones y desconcertantes trampas del lenguaje, que impedían una lectura directa, literal, de los textos e incitaban a una toma de distancia respecto a toda tesis dogmáticamente afirmada.

Pero precisamente por eso, para hacer justicia a Nietzsche como pensador, no bastaba con limitarse a encuadrarlo con solemnidad dentro de la historia de la metafísica, como de manera soberbia hiciera Heidegger en sus cursos universitarios a partir de 1936. Era preciso reconocer hasta qué punto la índole postmetafísica de su pensamiento había venido a ejercerse en el estilo mismo de su escritura. Aquello que el joven Nietzsche había articulado en las obras inmediatamente posteriores a El nacimiento de la tragedia bajo la categoría de lo "intempestivo", era lo que luego había proyectado formalmente en sus modos de expresión filosófica, subvirtiendo las convenciones del discurso lógico-conceptual de la tradición metafísica. Esto era algo que la obsesión por la eficacia histórica inmediata de sus ideas obturó por completo en todo este amplio periodo de recepción de su filosofía, estableciendo una continuidad de fondo entre las primeras mitificaciones y la instrumentalización ideológica subsiguiente. Ya fuese pensado como prototipo ideal de la raza aria (Baeumler), como perversa sublimación heroica para un beligerante capitalismo imperialista (Lukács) o como figura postburguesa del Trabajador en la era del dominio técnico del mundo (Jünger), el Uebermensch y, con él, todo el alcance de la propuesta nietzscheana de transvaloración de los valores quedaron consignados 
bajo los estrictos límites de aquello que se había hecho ya efectivamente presente en la primera mitad del siglo veinte no sólo como experiencia de nihilidad, sino incluso de aniquilación?

Tras la Segunda Guerra Mundial, al margen de una ortodoxia marxista apegada a la visión lukacsiana del filósofo como un irracionalista precursor del nazismo, los intentos de desnazificar a Nietzsche lo hicieron recurriendo fundamentalmente a una intensa despolitización de su pensamiento. Era algo que, a su manera, ya había explorado Thomas Mann en el periodo de entreguerras con su equívoco concepto de lo Unpolitischen ${ }^{8}$. La evidente estilización albergada en este recurso al apoliticismo nietzscheano dejaba insatisfecha, sin embargo, la necesidad de esclarecer las mediaciones textuales que habían posibilitado aquella penosa falsificación intelectual promovida por la ideología pangermanista del Tercer Reich. Paradójicamente, este silenciamiento dejó la puerta abierta a un trato más aséptico con sus escritos y, así, al imprescindible trabajo de depuración histórico-filológica tanto de su obra publicada como del material póstumo. Dicha labor, esbozada por estudiosos como Karl Schlechta o Erich F. Podach, no fue emprendida con resultados verdaderamente provechosos y perdurables hasta la edición crítica de Giorgio Colli y Mazzino Montinari, publicada en italiano por la editorial Adelphi a partir de 1964, en francés por Gallimard desde 1965 y en su idioma original por Walter de Gruyter desde 1967. En Alemania, la literatura académica de posguerra siguió esquivando pronunciarse en otros términos que no fueran los de la condena sumarísima o el revisionismo exculpatorio, presos por igual de una manera insuficiente de abordar la cuestión'.

En esa medida, fue en otras tradiciones intelectuales, que contaban con una trayectoria de recepción más abierta y plural de la filosofía nietzscheana, donde pudieron asentarse los estímulos más decisivos para encarar el controvertido tema de Nietzsche y el pensamiento político en una clave renovadora. El caso paradigmático fue el de la cultura francesa: desde el final de la Belle-Époque, en Francia se habían dado apropiaciones positivas del ideario nietzscheano

\footnotetext{
${ }^{7}$ Ernst Jünger: Der Arbeiter. Herrschaft und Gestalt. Hamburg, Hanseatische Verlagsanstalt, 1932; Gyorg Lukács, "Der deutsche Faschismus und Nietzsche" (1943) y, sobre todo, Die Zerstörung der Vernunft. Der Weg des Irrationalismus von Schelling zu Hitler, Berlín, Aufbau, 1954. Con esta condena radical por parte de Lukács se cortaría toda una línea de amplia recepción favorable de Nietzsche dentro de la tradición marxista, no recobrada hasta los años sesenta, principalmente en el contexto de la cultura francesa, mientras que en Alemania un gran epígono de la teoría crítica frankfurtiana como Habermas mantendría su juicio negativo.

${ }^{8}$ Thomas Mann, Betrachtungen eines Unpolitischen. Berlín, Fischer, 1918. El término aparece en los escritos nietzscheanos de la última época, sobre todo en los fragmentos póstumos fechados entre otoño de 1887 y marzo de 1888 (10 [91], 10 [135], 10 [157], 10 [181], 11 [363], 11 [377 y en El Anticristo (AC-27), con una connotación más bien peyorativa, y sólo en Crepúsculo de los ídolos con matiz positivo: "Todas las épocas grandes de la cultura son épocas de decadencia política: lo que es grande en el sentido de la cultura ha sido apolítico, incluso antipolítico" (GD-Deutsche-4).

${ }^{9}$ Sobre todo a partir de los setenta podemos hallar ya alguna que otra notable excepción, como el trabajo de Hennig Ottmann, Philosophie und politik bei Nietzsche. Berlín, Gruyter, 1978.
} 
por parte de movimientos libertarios, socialistas, feministas y europeístas; y ni siquiera durante los tiempos más oscuros de su forzada conversión en custodio de las esencias arias llegó allí a asentirse del todo a su imagen de "boche". El eco de la enérgica defensa realizada en 1915 por Henri Albert en su "Nietzsche contra los bárbaros" ${ }^{10}$ se prolongaba en la protesta de Georges Bataille en 1937, pidiendo que fuese lavado de la mancha nazi ${ }^{11}$. En acusado contraste con la imputación de semejante estigma, tanto la peculiar lectura existencialista de Bataille como las no menos intimistas de Pierre Klossowski o Maurice Blanchot incidían en nociones que sonaban a rebeldía - complot de las fuerzas, derroche vital, erotismo o transgresión-idóneas para quienes buscaban en Nietzsche un pensador que les permitiera superar las decepciones vividas con las recientes vanguardias estéticas y políticas. Estas lecturas sirvieron de puente para la gran rehabilitación de su filosofía llevada a cabo por una nueva generación, la de los Deleuze, Foucault, Lyotard o Derrida, que desde los años sesenta y durante la década de los setenta marcaron la agenda filosófica del postestructuralismo y suministraron nuevos impulsos al imaginario intelectual de la izquierda progresista. Agrupados bajo el rótulo de pensamiento de la diferencia, el genuino nexo en común de sus posiciones, a menudo bien dispares entre sí, fue justamente esa inspiración nietzscheana, sobre la base de la cual temas como el del fin de la modernidad, la superación de la metafísica, la muerte del hombre o el entrecruzamiento de verdad y poder pasaron a primer plano ${ }^{12}$. Se conjugaba de modo asistemático a los maestros de la sospecha -Marx, Freud, Nietzschecon especial pujanza de éste último, para esgrimir una crítica del sistema-i.e., del capitalismo- y su lógica del dominio, poniendo en cuestión el poder, las instituciones e incluso la manera misma de pensar y filosofar ${ }^{13}$. La enorme repercusión de toda esta corriente francesa posibilitó que la balanza exegética se inclinase de forma decisiva, haciendo que el Nietzsche reaccionario diese paso al Nietzsche posmoderno de la liberación, uno de cuyos intérpretes más destacados fue Gianni Vattimo ${ }^{14}$.

Por su parte, en Italia y España los estudios nietzscheanos supieron combinar esta tendencia hermenéutica con una línea de investigación más académica, insistiendo sobre todo en la contextualización histórica de sus

${ }^{10}$ Henri Albert, "Nietzsche contre les Barbares", en L'Opinion, 31.1.1915, pp. 60-62.

${ }^{11}$ Cfr. G. Bataille, "Nietzsche et les fascistes", en Acéphale, 2, 21 de enero de 1937, pp. 3-13.

12 Gilles Deleuze, Nietzsche et la philosophie, París, PUF, 1962; Michel Foucault, "Nietzsche, Freud, Marx", en Nietzsche. Cahiérs du Royaumont, Les Éditions du Minuit, 1964, pp. 183-192; «Nietzsche, la généalogie, l'histoire», en AA.VV., Hommage à Jean Hyppolite, París, P.U.F., 1971, pp. 145-172; Jacques Derrida, L'écriture et la différence. París: Seuil, 1967; Jean-François Lyotard, "Notes sur le retour et le kapital", en Nietzsche aujourd'hui? 10-18. Vol. 1, París, Publications du Centre culturel internationel de Cerisy-la-Salle, 1973, pp. 141-157.

13 Catherine Halpern, «Éditorial» para Foucault-Derrida-Deleuze: Pensées rebelles, en Sciences Humaines (2005). Numéro Spécial Hors-Serie 3.

14 Vid. sobre todo Gianni Vattimo, Il soggetto e la maschera. Nietzsche e il problema della liberazione. Milán, Bompiani, 1974; Le avventure della differenza, Milán, Garzanti, 1980. 
ideas, tal como hizo la escuela de Montinari (Giuliano Campioni y discípulos suyos como María Cristina Fornari, Paolo D'Iorio, etc. ${ }^{15}$, o abriéndose a debates filosóficos de actualidad, como ocurrió en el caso de los principales integrantes del grupo editor de los fragmentos póstumos y las obras completas de Nietzsche en castellano, con Diego Sánchez Meca a la cabeza ${ }^{16}$. En varias publicaciones previas a mi incorporación a dicho grupo es donde defendí la idea de un Nietzsche heredero intempestivo del criticismo ilustrado, que aplica a la razón moderna su propio ejercicio desmitificador para poner en evidencia cómo ésta no alcanza a desprenderse por completo de ciertos esencialismos metafísicos, sin que esto suponga necesariamente renegar sin más de su caudal emancipatorio.

En cuanto al ámbito anglófono, en un primer momento se adoptó también esa estrategia defensiva consistente en procurar cortar el vínculo entre la filosofía nietzscheana y el nacionalsocialismo a base de subrayar las cualidades antipolíticas e individualistas de su pensamiento. La conocida monografía de Walter Kaufmann, Nietzsche. Philosopher, Psychologist, Antichrist, publicada en 1950, resultó paradigmática en ese sentido. Pero desde los años setenta la cuestión comenzó a plantearse en otros términos: ¿podía aportar algo Nietzsche al intento de repensar la democracia? Visiones más convencionales trataron de esquivar el asunto declarando la ineptitud de Nietzsche para un pensamiento político serio, o bien insistiendo en su estricto apego a un ordenamiento social antidemocrático ${ }^{17}$. En un comentado artículo, Martha Nussbaum le reprochaba al mismo tiempo tanto lo uno cuanto lo otro ${ }^{18}$. Pero otros intérpretes, filtrando la lectura postestructuralista de Nietzsche, vislumbraron el potencial de su crítica al subjetivismo y humanismo modernos para activar una revisión de la filosofía política capaz de desbordar el modelo liberal, procedimentalista y deliberativo que había dominado la escena teórica contemporánea a partir de la obra de pensadores como John Rawls o Jürgen Habermas ${ }^{19}$. Desde entonces, la controversia no ha dejado de crecer, se ha extendido al ámbito general de la

15 Vid. v.g. Giuliano Campioni, Sulla strada di Nietzsche. Pisa, ETS, 1992; María Cristina Fornari, La morale evolutiva del gregge. Nietzsche legge Spencer e Mill, Pisa, ETS, 2006; Paolo D'Iorio, Le voyage de Nietzsche à Sorrente. Gènese de la philosphie de l'esprit libre. París, CNRS, 2012. Ajenos a la seriedad de estas lecturas filológicamente rigurosas, contextualizadas históricamente, ha habido también notorios intentos de reafirmar una relación directa entre las ideas nietzscheanas y el nazismo (Maurizio Ferraris, ed., Nietzsche. Bari, Laterza, 1999), incluso en aquellos aspectos más claramente combatidos por el filósofo, como es el caso del antisemitismo (Domenico Losurdo, Nietzsche, il ribelle aristocrático. Turín, Boringhieri, 2002).

16 Diego Sánchez Meca, Nietzsche: la experiencia dionisíaca del mundo, Madrid, Tecnos, 2005.

17 Bruce Detwiler, Nietzsche and the Politics of Aristocratic Radicalism, Chicago, University of Chicago Press, 1990.

${ }_{18}$ M. Nussbaum, "Is Nietzsche a Political Thinker?", en International Journal of Philosophical Studies, 5 (1997), pp. 1-13.

${ }^{19}$ Cfr. v.g. Alan D. Schrift, «Le nietzschéisme comme épistemologie. La réception française de Nietzsche dans le moment philosophique des années 1960» en Patrice Maniglier (ed.), Le moment philosophique des années 1960 en France. París, PUF, 2011, pp. 95-109.

Araucaria. Revista Iberoamericana de Filosofia, Política, Humanidades y Relaciones Internacionales, año $23, \mathrm{n}^{\circ} 46$. Primer cuatrimestre de 2021. Pp. 241-271. ISSN 1575-6823 e-ISSN 2340-2199 https://dx.doi.org/10.12795/araucaria.2021.i46.12 
Nietzsche Forschung e incluso lo ha desbordado en gran medida. Así, en las últimas décadas, autores como William E. Connolly, Bonnie Honig o Chantal Mouffe se han remitido expresamente a Nietzsche como una de sus fuentes de inspiración para desarrollar una propuesta alternativa a las teorías políticas basadas en el consenso, la conocida comúnmente con el rótulo de "agonismo político" 20 . En lo que sigue, trataré de argumentar qué aspectos significativos del pensamiento nietzscheano me parecen susceptibles de ser interpretados como aportes para una crítica democrática de la democracia y dónde veo un límite difícilmente salvable para hacer productivas sus ideas en ese sentido.

¿En qué sentido es Nietzsche, entonces, un pensador político? Y, de serlo, ¿en qué medida es propiamente uno al que se le pueda atribuir un agonismo político? Desde luego, no cabe decir que de su obra se desprenda con claridad meridiana un posicionamiento que encaje en nuestros esquemas y ocupe un lugar definido dentro del espectro político habitual. Ni tampoco que la práctica de extraer implicaciones políticas de determinados pasajes aislados se haya revelado muy exitosa. Ahora bien, eso no significa que su filosofía carezca de proyección política. Sólo que el camino hacia una comprensión ponderada de la misma es indirecto. Nietzsche expresa a veces su parecer sobre asuntos políticos concretos, pero no se prodiga demasiado al respecto. Suele mostrar una actitud bastante desdeñosa hacia todo cuanto tiene que ver con la política o la economía. Su talante fundamental, como el de Zaratustra, es el de alguien que quiere mantenerse alejado de las "moscas del mercado", de aquellos que reducen el valor de la vida al mero bienestar material, sospechando que lo que subyace a esta perspectiva utilitarista extendida en la modernidad es la tendencia a conformar un tipo de hombre mediocre, adocenado, incapaz de criterio propio y genuina libertad de espíritu. En esto adopta por principio una posición similar a la de su venerado Jacob Burckhardt, quien consideraba que entre cultura y Estado existe un antagonismo insalvable y que, para prosperar, la primera ha de quedar a salvo del segundo ${ }^{21}$. Nietzsche entiende que el Estado

${ }^{20}$ Chantal Mouffe, The Return of the Political. Londres-New York, Verso, 1993; Bonnie Honig, Political Theory and the Displacement of Politics, Ithaca/NY, Cornell University Press, 1993; William Eugene Connolly, Identity|Difference: Democratic Negotiations of Political Paradox. Minneapolis, University of Minnesota Press, 2002; Pluralism. Durham, Duke University Press. 2005. Con algo de ambigüedad, en Connolly se vuelve a combinar la afirmación de que el pensamiento nietzscheano carece de configuración política definida con la confianza en su plena adecuación a un marco democrático. Cfr. W. Connolly, Identity|Difference, p. 197; así como Mark Redhead and William Connolly, "Nietzsche and Liberal Democracy: a Relationship of Antagonistic Indebtedness?" The Journal of Political Philosophy, vol. 5, no. 2 (1997), pp. 183-193.

${ }^{21}$ GD-Deutsche-4: "La cultura y el Estado - no nos engañemos al respecto- son antagonistas: el 'Estado de cultura' es simplemente una idea moderna. Lo uno vive de lo otro, lo uno prospera 
ha de ser básicamente un instrumento de gobierno y gestión que permita el despliegue de aquellos valores que potencian y elevan el nivel cultural de una sociedad. Sin embargo, considera que la tendencia cada vez más acentuada del Estado moderno invierte esta relación, practicando además una intromisión en todos los ámbitos de la vida, que amenaza con agostar esta esfera de cultivo autónomo del espíritu y someterla a un poder unilateral. Y esto es así porque, en lugar de actuar como garante de ese espacio de libre expresión de una pluralidad de valores, el Estado burgués tiende a someterlo al monopolio de los intereses económicos. Con ello, por cierto, desnaturaliza su función más propia, se despolitiza de hecho, al dejar que los grandes poderes económicos y las grandes corporaciones industriales lo instrumentalicen y, junto a él, al conjunto de la sociedad". La consecuencia que Nietzsche vislumbra es la progresiva privatización de los asuntos estatales en manos de nuevas oligarquías ${ }^{22} \mathrm{y}$, significativamente, contra la letra de su orgulloso título de "democrático", la pervivencia en el Estado moderno de la vieja distinción entre gobierno y pueblo, como si de dos esferas de poder separadas se tratara ${ }^{23}$. Al contemplar nuestro presente y ver hasta qué punto ámbitos prioritarios como el de la educación o la sanidad se ven zarandeados tanto por intereses privatizadores como por políticas públicas mediocres, que en el fondo comparten el prejuicio de que la excelencia se mide en términos de rendimiento económico, hay que admitir que el pronóstico nietzscheano sobre la decadencia de nuestras instituciones (en particular, las de enseñanza "superior" $)^{24}$ no era infundado.

a expensas de lo otro". Cfr. Rolf Elberfeld, "Durchbruch zum Plural. Der Begriff der Kulturen bei Nietzsche", en Nietzsche-Studien 37, 2008, pp. 115-142. Según Elberfeld, de Burckhardt habría tomado también Nietzsche el empleo del término en plural, enfatizando su dinamismo y diversidad.

${ }^{22}$ MA, I, 472: "Las sociedades privadas irán absorbiendo paulatinamente los asuntos de Estado. Incluso el residuo más pertinaz que quedará del antiguo trabajo del gobierno (por ejemplo, la tarea de mantener seguros a los particulares frente a los particulares) acabará un día por ser encargado a los empresarios privados".

${ }^{23}$ MA, I, 450: "Nuevo y viejo concepto de gobierno. Distinguir entre gobierno y pueblo, como si aquí se tratase de dos esferas de poder separadas, una más fuerte, superior, y otra más débil, inferior, que negociaran y se pusieran de acuerdo, es parte de un sentimiento político heredado que aún hoy día sigue correspondiendo a la configuración histórica de las relaciones de poder en la mayoría de los Estados. Cuando, por ejemplo, Bismarck define la forma constitucional como un compromiso entre gobierno y pueblo, habla conforme a un principio que tiene su razón en la historia (por supuesto que también encuentra ahí precisamente su grano de irracionalidad, sin el cual nada humano puede existir). Ahora bien, debe aprenderse -conforme a un principio que ha surgido puramente de la cabeza y que aún tiene que hacer historia- que el gobierno no es nada más que un órgano del pueblo, no un providencial, venerable 'arriba' con relación a un 'abajo' habituado a la modestia". En una versión anterior de este aforismo, Nietzsche añadía esta curiosa observación: "Quien no pueda franquear esta separación, seguirá teniendo en todas las demás situaciones la vieja mentalidad del esclavo en relación con el amo".

24 "Lo que las 'escuelas superiores' de Alemania logran de hecho es un adiestramiento brutal para, con la menor pérdida posible de tiempo, hacer utilizable, aprovechable para el servicio del Estado a un gran número de jóvenes" (GD-Deutsche-5). Faltan educadores, dice ahí mismo Nietzsche, citando como excepción a Burckhardt, "a quien Basilea debe su primacía en humanidades", mientras que en todas partes las universidades se pliegan a la exigencia inmediata de suministrar "profesiones" al mercado laboral, en lugar de cultivar vocaciones con todo el tiempo y la paciencia precisos para ello. 
En cualquier caso, resulta evidente que el punto de vista prioritario de Nietzsche, cuando aborda cuestiones de esta naturaleza, es el de la regeneración de la cultura. Esto es algo que puede apreciarse a lo largo de toda su trayectoria intelectual, desde El nacimiento de la tragedia hasta las obras de madurez tardía, pasando por sus Consideraciones intempestivas o por su extensa e interesante "Ojeada al Estado" en la primera parte de Humano, demasiado humano, de donde proceden ideas como las que acabamos de exponer más arriba. Las contadas apelaciones finales a una "gran política", en la medida en que han quedado en esbozo, apenas añaden nada verdaderamente esclarecedor a la preocupación de sus últimos escritos por la forja de un tipo superior de humanidad. Éste el genuino problema de Nietzsche: en qué condiciones pueden los individuos cultivar ahora su voluntad de autosuperación, su sentimiento de distinción y su responsabilidad personal, contrarrestando una dinámica de las "ideas modernas" que, a su juicio, marcharía en sentido contrario. No se trata de un problema que estime susceptible de resolverse con meros cambios en las instituciones de gobierno. Por eso su atención preferente se dirige a la crítica de la moral, a la pregunta por los valores y a la exploración psicológica del individuo. De ahí que para algunos de sus intérpretes el aristocratismo nietzscheano se halle ligado al perfeccionismo y resulte desorientador situarlo en un plano político, cuando de hecho su foco principal vendría a ser el de la ética y la acción individual. Así lo han entendido autores como Stanley Cavell o, con matices, Daniel Conway ${ }^{25}$. Sin embargo, como ha señalado con acierto Vanessa Lemm, esta lectura del presunto perfeccionismo nietzscheano descuida el hecho de que, en Nietzsche, la libertad del individuo no procede de una subjetividad encapsulada, sino que se constituye en el espacio público del combate cultural con otras formas de vida, con las que se contrasta y frente a las que busca distinguirse ${ }^{26}$.

En este punto es donde cobra el mayor interés confrontarse con la idea de agonismo en Nietzsche. Ciertamente, sólo en las últimas décadas se ha convertido en un tópico recurrente dentro de la literatura especializada sobre Nietzsche su interpretación del agón griego ${ }^{27}$. Pero esto no significa en absoluto

${ }^{25}$ Stanley Cavell, Conditions Handsome and Unhandsome: The Constitution of Emersonian Perfectionism. University of Chicago Press, 1990; Daniel W. Conway, Nietzsche and the Political. Londres, Routledge, 1997. Digo "con matices", porque Conway habla también de un perfeccionismo político en Nietzsche, pero lo supedita a un perfeccionismo moral, que concibe como un ejercicio individual de resistencia anti-institucional.

${ }^{26}$ Vid. Vanessa Lemm, "Nietzsche y la democracia liberal. John Rawls, Stanley Cavell y la política de la cultura", en Nietzsche y el pensamiento político contemporáneo, Chile, FCE, 2012, pp. 31-64.

${ }^{27}$ Además del ya citado de Lemm, otros trabajos destacados en este sentido: Lawrence J. Hatab, A Nietzschean Defense of Democracy: An Experiment in Posmodern Politics, Chicago, Open Court, 1995; Id., "Prospects for a Democratic Agon: Why We Can Still Be Nietzscheans", Journal of Nietzsche Studies 24 (2002): 132-147; Herman Siemens, "Agonal Communities of Taste: Law and Community in Nietzsche's Philosophie of Transvalutation", Journal of Nietzsche Studies 24 (2002): 83-112; Christa Davis Acampora, Demos Agonistes Redux: Reflections on the Streit of Political 
que la cuestión de fondo que a través de dicho tópico se aborda sea un asunto menor, ni que haya sido descuidada anteriormente por la Nietzsche-Forschung; pues se trata ni más ni menos que de la cuestión del carácter insuperablemente conflictivo de la vida humana $\mathrm{y}$, al hilo de ella, la de la condición trágica de la existencia. Dicho de otro modo: se trata de uno de los aspectos nucleares de la concepción nietzscheana del mundo como voluntad de poder. Por tanto, hablamos aquí de una temática que atraviesa y vertebra toda la obra del filósofo, si bien la frecuencia con la que suele aparecer formulada en estos específicos términos, que remiten a la cultura helénica y a la importancia que tuvo en ella el espíritu competitivo ${ }^{28}$, resulte significativamente menor. Basta con hacer un rápido rastreo por la versión digital de la edición crítica del corpus nietzscheano $(\mathrm{eKGWB})^{29}$ para comprobar que la palabra "Agon" aparece tan sólo en nueve ocasiones dentro de siete unidades textuales; "agonale" ocurre ocho veces; "agonalen", once; y otras variantes como "agonal", "Agons", "Agone" o "Agonen", una o, a lo sumo, dos veces. Si nos limitamos a sus escritos de madurez, son poco más de diez las apariciones del término o sus variantes: aparte de unas cuantas menciones aisladas en los fragmentos póstumos, Nietzsche sólo lo emplea en una de sus obras publicadas, en Crepúsculo de los ídolos, para referirse con carácter genérico al "impulso agonal de los helenos" (GD-Sokrates, 8) y para definir en concreto "la filosofía, a la manera de Platón" (...) "como una competición erótica, como un perfeccionamiento e interiorización de la vieja gimnástica agonal y de sus presupuestos", de la que acabaría brotando "una nueva forma del agón griego, de la dialéctica" (GD-Streifzuege-23). Considérese que un vocablo como "Kampf" (lucha) registra una ocurrencia de unas quinientas cincuenta veces en los textos del filósofo y "Macht" (poder), más de tres mil. El término alemán que traduce el agón griego, "Wettkampf", y sus variantes aparecen con mayor frecuencia en torno al año de El nacimiento de la tragedia, para luego reducirse de manera considerable. Así pues, la dedicación explícita al agón griego posee cierto carácter episódico en la obra de Nietzsche y se circunscribe esencialmente a algunos escritos filológicos del primer período. ¿Por qué, pues, tanta insistencia en él? Mi impresión es la de que, si el término ha hecho especial fortuna en la interpretación contemporánea de Nietzsche, ha sido en gran medida por su idoneidad para conectarlo con el debate en torno a una democracia radical y, de manera más específica, con una concepción del antagonismo político

Agonism, Nietzsche-Studien 32 (2003): 374-390; Siemens y H. Vasti Roodt (eds.), Nietzsche, Power, and Politics: Rethinking Nietzsche's Legacy for Political Thought, Berlín, De Gruyter, 2008.

${ }^{28}$ En griego antiguo, la palabra "agón" se usa para referirse a toda clase de competiciones. Así, los juegos olímpicos: Agón Olympias. La forma verbal es "agein", que significa liderar, traer, conducir, tasar y celebrar.

${ }^{29}$ Digitale Kritische Gesamtausgabe Werke und Briefe, basada en la edición crítica de G. Colli y M. Montinari (KGWB: Berlín/New York, de Gruyter 1967ss.) y editada por Paolo D’Iorio: http:// www.nietzschesource.org.

Araucaria. Revista Iberoamericana de Filosofí, Politica, Humanidades y Relaciones Internacionales, año $23, \mathrm{n}^{\circ} 46$. Primer cuatrimestre de 2021. Pp. 241-271. ISSN 1575-6823 e-ISSN 2340-2199 https://dx.doi.org/10.12795/araucaria.2021.i46.12 
inspirada por el pensamiento de Carl Schmitt, clave recurrente en filósofos de la llamada izquierda foucaultiana para poner en cuestión una visión liberal de la democracia. Consideraré luego algunas posibles incongruencias presentes en esta asimilación. Pero antes fijemos nuestra atención en el texto nietzscheano que más extensamente se ocupa del instinto agonal de los griegos. Se trata del último de los Cinco prólogos a cinco libros no escritos, compuesto en 1872, y lleva por título "El certamen de Homero".

Ya en julio de 1867 el joven filólogo había pronunciado una conferencia sobre la competición de los aedos de Eubea, donde analizaba el relato legendario transmitido por un texto del siglo II sobre la presunta celebración de un concurso poético entre Homero y Hesíodo ${ }^{30}$. Aludiendo a este asunto, así como a la existencia de una versión más antigua del poema de Hesíodo, Los trabajos y los días, que se iniciaría, no con el himno a Zeus, sino con la distinción entre dos diosas, ambas llamadas Eris (discordia), una buena y otra mala, Nietzsche desarrolla en El certamen de Homero una sugerente teoría sobre el sentido del agón en la cultura helénica ${ }^{31}$ : la rivalidad, la pelea, la tensión del combate, nos dice, eran para los griegos parte esencial de la vida. A diferencia del "blando concepto de la humanidad moderna" (CV5: OC, I, 562), nunca entendieron que los atributos "naturales" y los llamados realmente "humanos" estuvieran separados entre sí, sino profundamente entrelazados. De modo que aceptaron también como parte de su humanidad sus instintos más violentos y crueles, en lugar de pretender extirparlos de raíz. Sin embargo, poco a poco fueron aprendiendo a encauzar su necesidad de desahogarlos de la manera más terrible y destructiva - esto es, bajo la modalidad de lo que Hesíodo calificó como la Eris "mala"- y a hacerlo de forma mucho más atemperada, según reglas y códigos de conducta, convirtiendo la guerra sin cuartel en un enfrentamiento festivo, incruento, en el que se rivalizaba por el logro de honores y distinciones. Así es como se desplegó en la Grecia clásica toda una cultura de la competitividad, plasmada tanto a través del cuerpo como de la palabra, ya fuese en la palestra, en contiendas deportivas, como las de los Juegos Olímpicos, o en disputas retóricas como las sostenidas en el ágora y en el teatro ${ }^{32}$. La doma de caballos, la propia acción guerrera o el incesante litigio entre las ciudades-Estado se tiñeron igualmente de este sentido agonal. El arte griego se pobló de cuerpos humanos en tensión, mientras la fantasía popular no dejaba de recrearse en las imágenes de combate de la Ilíada (ibid. 563). Nietzsche señala cómo fue

\footnotetext{
${ }^{30} \mathrm{Su}$ estudio del códice en el que se preservó dicho texto, El tratado florentino sobre Homero y Hesíodo, su origen y su certamen, se publicó en dos entregas, entre 1870 y 1873, en la revista Rheinisches Museum für Philologie. Vid. KGW II 1: 271-337= OC II, 233-289.

${ }_{31}$ Acampora, Ch. D. «The Contest between Nietzsche and Homer: Revaluing the Homeric Question», en N. Martin (ed.), Nietzsche and the German Tradition, Oxford/N. York, Lang, 2003: 83-109.

${ }^{32}$ En el teatro, por ejemplo, se escenificaba el debate entre dos personajes, el proto-agonista, que era el primero en hablar, y el segundo agonista, que era el llamado a vencer en la discusión, al tener la última palabra.
}

Araucaria. Revista Iberoamericana de Filosofia, Politica, Humanidades y Relaciones Internacionales, año $23, \mathrm{n}^{\circ} 46$. Primer cuatrimestre de 2021. Pp. 241-271. ISSN 1575-6823 e-ISSN 2340-2199 https://dx.doi.org/10.12795/araucaria.2021.i46.12 
esta forma sublimada de la agonística la que permitió superar la noche y el horror de aquel mundo prehomérico, dominado aún por los impulsos más sangrientos, en el que Grecia estuvo a punto de ceder al pathos orientalizante y a su sentimiento de asco ante un mundo de pura lucha y crueldad (id.). Como escribiera en un destacado pasaje de El nacimiento de la tragedia ${ }^{33}$, anticipando el estilo genealógico de su indagación de madurez sobre el carácter plástico, dinámico, de las fuerzas instintivas: en vez de ceder a las bestias más salvajes de la naturaleza, los griegos fueron capaces de transfigurar esos impulsos y convertirlos en ocasión de fiesta y juego, en celebración jubilosa del placer de la existencia, incluido en ello el placer de vencer, de dominar, de ser mejor. Así vino a constituirse el carácter más definitorio de la Bildung helénica, de su pedagogía, para la cual "todo talento debe desarrollarse luchando" (ibid., 566). Para una mentalidad como ésa, no había por qué condenar en bloque rasgos humanos como el egoísmo o la ambición, sino sólo sus modalidades reactivas. Por eso escribe Nietzsche:

Toda la antigüedad griega piensa de manera distinta a nosotros respecto al rencor y a la envidia y opina lo mismo que Hesíodo, que por un lado califica de mala a una Eris, que llevaba a los hombres a enfrentarse unos contra otros en una lucha hostil de aniquilamiento, y por otro lado alababa como buena a una segunda Eris, que, bajo forma de celo, rencor y envidia, incitaba a los hombres a la acción, pero no ya a una lucha de aniquilamiento, sino al acto del certamen. El griego es envidioso, y no consideraba este atributo como un defecto, sino como el efecto de una divinidad bienhechora: ¡Qué abismo entre nuestro juicio ético y el suyo! (OC, I, 564).

Nietzsche considera que los griegos supieron orientar esa envidia en clave positiva, a modo de acicate para despertar un sentimiento de emulación y, sobre todo, un afán de distinguirse como individuos, que fue lo que les llevó a la excelencia. Tal como pone de relieve el pasaje citado, toda esta reconstrucción del papel fundamental del agón en la cultura helénica se realiza en acusado contraste con la cultura moderna. Se diría que Nietzsche traslada a su propio ejercicio intelectual ese pathos agonal, espoleando con su crítica a la conciencia autosatisfecha de su propio tiempo y poniendo ante ella a un rival difícil de aventajar. Donde esto se expresa de la manera más pregnante es justamente a propósito de la rivalidad política. En su sentido moderno, escribe Nietzsche, el genio posee carácter de "exclusividad" (ibíd., 566). Pero la idea griega del genio "presupone que, en el orden natural de las cosas, existen siempre varios genios, que se estimulan recíprocamente a la acción, de la misma manera que también se mantienen recíprocamente en los límites de la mesura. Ésta es la esencia de la concepción helénica del certamen: aborrece el dominio exclusivo

\footnotetext{
${ }^{33}$ Cfr. OC, I, 343.
} 
y teme sus peligros, desea como medio de protección contra el genio -un segundo genio" (idem). Así habría ocurrido de manera significativa en el caso del genio político. Nietzsche se remite al ejemplo de los efesios, con motivo del destierro de Hermodoro, para ilustrar lo que sería el significado originario del ostracismo, según una cita tomada del fragmento 114 de Heráclito en la que puede leerse: "Entre nosotros ninguno ha de ser el mejor; pero si alguno lo es, que lo sea en otra parte y entre otras gentes". Este mecanismo de autodefensa contra la tiranía, practicado sobre todo por las facciones aristocráticas atenienses en el primer cuarto del siglo $\mathrm{V}$ a. C., es interpretado por Nietzsche como un instrumento para garantizar la salud del Estado, en la medida en que su objetivo último sería la preservación del conflicto político:

\begin{abstract}
Pero, ¿por qué ninguno debe ser el mejor? Porque con ello ya no habría certamen (agón), y el eterno fundamento vital del Estado griego estaría en peligro. Más tarde el ostracismo asume otra posición respecto al agón: se aplica cuando es patente el peligro de que uno de los grandes políticos y jefes de acción que luchan en la contienda se sienta incitado, en el ardor de la lucha, a servirse de medios dañinos y destructivos, y a intentar peligrosos golpes de Estado. El sentido primitivo de esta peculiar institución no es sin embargo el de una válvula de escape, sino el de un estimulante: se elimina al individuo que destaca, a fin de que se despierte de nuevo el juego agonístico de las fuerzas (OC, I, 565-566).
\end{abstract}

A renglón seguido de esta original lectura del ostracismo, Nietzsche hace una última observación, de gran interés para captar la relevancia política de su comprensión del agón griego. Una vez más, su descripción del estilo de vida helénico viene acompañada del propósito de establecer un punto de contraste con la actitud de los modernos, en quienes el cultivo egoísta del individuo y la entrega al bien común parecen necesariamente obligados a escindirse. Y añade:

En cambio, para los antiguos, la meta de la educación agonal era el bienestar de la colectividad, de la sociedad estatal. Cada ateniense, por ejemplo, debía desarrollar agonísticamente su personalidad en la medida en que pudiese ser para Atenas de la máxima utilidad y la perjudicase lo menos posible. No había una ambición desmesurada e inconmensurable, como ocurre la mayoría de las veces con la ambición moderna: cuando competía en la carrera, en el lanzamiento o en el canto, el joven pensaba en el bien de su ciudad materna; quería aumentar su fama para aumentar la fama de su ciudad; ofrecía a los dioses de la ciudad la corona que los jueces de la contienda ponían sobre su cabeza como signo de honor. Cada griego sentía en sí, desde la infancia, el deseo ardiente de ser un instrumento en el certamen de las ciudades, para salvar a su ciudad de su ciudad: por este deseo su egoísmo se encendía, y en él se refrenaba y limitaba (ibíd., 566). 
Está claro por qué destacados intérpretes de Nietzsche han podido hallar en este texto suyo de juventud un cúmulo de sugerencias teóricas que permiten aproximar su pensamiento a los parámetros de una democracia agonista: el rechazo de toda forma de imposición violenta, de actitud tiránica -e incluso de hegemonía política concentrada en un único poder-resulta aquí bien explícito. La supremacía de un único genio es condenada como hybris. Son posicionamientos que cabe entender como solidarios con una defensa del pluralismo. Y, en efecto, Nietzsche asume en su propia filosofía, en su actitud misma ante la vida, que el despliegue del juego agonal de las fuerzas requiere como condición indispensable el que su pluralidad se fomente, el que no se vea restringida; o, dicho de otro modo, requiere de la existencia de rivales que inciten a competir y a quienes no se pretenda anular, sino sólo vencer en el caso puntual de cada encuentro. Justamente porque no hay supresión del otro (pues no estamos aquí, como precisa Nietzsche, en una Vernichtungskampf: en una guerra de exterminio), se tratará siempre de una victoria parcial, limitada, que no cierre la posibilidad de volver a enfrentarse otra vez al contrincante en buena lid, puesto que es del certamen de donde deriva el sentimiento de poder, de autoafirmación vital. Y si dicho sentimiento se busca por satisfacción personal, no menos se persiguen el honor y la fama en tanto signos de reconocimiento de que también la polis encuentra recompensa en esta dinámica de autosuperación. Así pues, Nietzsche no sólo valora el agón como un medio para la excelencia individual. Expresamente se refiere a su función como garante del bienestar social. Lecturas como la de Connolly, que interpretan la ética nietzscheana de la superación personal como una ética estrictamente individualista, sin alcance en el plano de la colectividad, se ven seriamente comprometidas por este planteamiento ${ }^{34}$. No es sólo que el certamen se desarrolle ante un público y que forme parte de su valor la puesta en escena, la belleza de la victoria ante testigos. Es que el concurso sólo tiene sentido en la medida en que todos los rivales aceptan de partida, de mutuo acuerdo, unas reglas establecidas por la comunidad y las respetan hasta el final. De lo contrario, se produce un ensañamiento sanguinario y estéril, que conduce a la anarquía de las fuerzas y a la desaparición de la comunidad ${ }^{35}$. Por más que lo ansiado por parte del individuo

${ }^{34}$ Esto es lo que lleva a Connolly a decir, v.g., que su propuesta de una democracia agonista y pluralista, más que un desarrollo de la filosofía de Nietzsche, a la que considera carente de estructura política definida, es una "tematización política de sentimientos nietzscheanos" (Identity|Difference, ed. cit., p. 19). Es Foucault quien marca el sentido de esta suplementación política de Nietzsche en Connolly y otros teóricos del agonismo político como Leslie Paul Thiele ("The Agony of Politics: The Nietzschean Roots of Foucault's Thought", en American Political Science Review 84, 3 (1990): 907-925).

${ }_{35}$ Cfr. la alusión de Nietzsche "al sanguinario e insaciable ensañamiento mutuo de dos bandos griegos, por ejemplo, en la revolución de Corcira" (OC, I, 562). Vid. también FP, I, 16 [39]: "La revolución de Corcira como lucha de exterminio entre dos partidos. Por el contrario, en Atenas, una especie de certamen"; así como El caminante y su sombra, 31: "Pero si la comunidad social se hunde por completo y todo cae la anarquía, reaparece en seguida el estado de naturaleza, la desigualdad temeraria y sin escrúpulos, como ocurrió en Corcira, según el relato de Tucídides. No hay justicia natural ni injusticia natural".

Araucaria. Revista Iberoamericana de Filosofia, Política, Humanidades y Relaciones Internacionales, año $23, \mathrm{n}^{\circ} 46$. Primer cuatrimestre de 2021. Pp. 241-271. ISSN 1575-6823 e-ISSN 2340-2199 https://dx.doi.org/10.12795/araucaria.2021.i46.12 
sea la distinción, el marcar la diferencia, por más que las fuerzas y capacidades no sean las mismas en cada uno de ellos, existe esta homologación de base, que es lo que hace honorable la contienda y la victoria, manteniéndola dentro de límites aceptables. Semejante equiparación se halla, indudablemente, al servicio de la proliferación de diferencias, funciona como estímulo para la libre competencia, pero implica a la vez la conciencia de que el otro es un igual, alguien digno de ser tenido como un rival. Es por tanto la articulación entre esta forma básica de isonomía y el cultivo de la excelencia la que sirve de base a algunos autores para sostener la posibilidad de un encuentro entre democracia y aristocratismo en el pensamiento nietzscheano. Lo que resulta evidente es que la asunción de estos elementos permea el conjunto de su filosofía y confiere su carácter más definitorio a una ética inspirada en el poder creativo del conflicto, cuya clave reside en el reconocimiento de que el adversario es alguien que nos ayuda en nuestra aspiración a ser mejores y a quien, por consiguiente, hemos de estar agradecidos.

La doctrina heraclítea de que los opuestos son amigos, de que la armonía proviene del contraste y de que la mesura nace de la fuerza para contener los extremos constituye, sin duda, una perfecta plasmación filosófica de este espíritu agonal. De Heráclito a Platón, esto es lo que el joven filólogo reconoce como rasgo más distintivo de la cosmovisión griega. Cuando escribió El certamen de Homero, el joven Nietzsche acababa de proyectar dicho rasgo en su hipótesis sobre el surgimiento de la tragedia griega a partir del conflicto permanente entre Dionisos y Apolo. En su obra de madurez, permanecerá fiel a este pensamiento fundamental. Su concepción del mundo como voluntad de poder sigue otorgando al pólemos una dimensión ontológica. $\mathrm{Su}$ crítica de la metafísica cuestiona toda pretensión de creerse en posesión de una verdad absoluta, promoviendo el perspectivismo. Ahora bien, estos aspectos no están reñidos en Nietzsche, como no lo estaban en Heráclito, ni en Platón, ni en la mentalidad griega en general, con una clara tendencia aristocratizante. Es ahí donde surge el debate. No hay que olvidar que un historiador de la antigua Hélade tan prestigioso y tan influyente en Nietzsche como su admirado colega de Basilea, Jacob Burckhardt, con quien el filósofo comparte el mérito de haber revelado el lugar central del agón en el mundo griego, sitúa netamente "el desenvolvimiento de la vida agonal por parte de individuos destacados" en el apartado de su Historia de la cultura griega dedicado a la aristocracia: fueron los menos, los privilegiados que podían permitirse el lujo de no tener que trabajar para su sustento y dedicar el tiempo libre al entrenamiento atlético, retórico, artístico o del tipo que fuere, quienes fomentaron esas prácticas competitivas, exhibiéndose con ellas ante el resto de la población. Cierto es que este espíritu agonal se fue extendiendo luego a las distintas esferas de la vida y acabó convirtiéndose en una característica fundamental de toda aquella sociedad y cultura, siendo de hecho los juegos 
panhelénicos los que confirieron a los griegos una identidad nacional, carentes como estaban de gobierno central. Pero Nietzsche tiene bien presente que la institución del agón surgió como un fenómeno diferenciador dentro de la clase aristocrática. Conviene, pues, medir bien en qué sentido su apuesta por una moral de señores que combata el gregarismo y la mediocridad del europeo moderno no sigue aún apegada al molde de esta forma aristocrática de cultura superior, comprometiendo sus intuiciones más luminosas en torno al modo en que el potenciamiento excepcional de la salud y vitalidad de un individuo puede redundar en beneficio del conjunto de la sociedad.

En mi primer libro sobre Nietzsche defendí el valor de esta impronta agonística de su filosofía, que sobre todo es concebida por él como una dinámica de auto-superación, no sólo aplicable al individuo, sino a la cultura y a la vida misma. Es lo que ahí expresaba ya desde el título mismo de mi trabajo con la idea de La voluntad de poder como amor: la convicción de que el auténtico ejercicio del poder -de Selbstüberwindung- no se realiza en la dominación del otro, en su sojuzgamiento y anulación, sino en la entrega generosa y confiada de uno mismo, en el derroche vital, en la donación de sí, tal como ocurre en el amor y en esa voluntad de ocaso distintiva de la "virtud que hace regalos" de la que habla el Zaratustra ${ }^{36}$. "El que ama vale más, es más fuerte", escribe asimismo Nietzsche en un fragmento póstumo de primavera de 1888, encabezado por la palabra Liebe: "El que ama se prodiga, es lo bastante rico para ello" (FP, 14 [120]). La sobreabundancia, el exceso de fuerza que supone esta experiencia del amor, se vierte sobre lo ajeno; cancela, pues, todo afán de auto-preservación e invita propiamente a un desmontaje del yo, en tanto es literalmente "olvido de sí", esto es, asunción de la propia responsabilidad en el cuidado del otro. De este modo, la articulación entre creación de valores y donación de sí, entre poder y amor que recorre todo Así habló Zaratustra, invita a pensar una idea de reconocimiento que deja en suspenso toda concepción reactiva de las relaciones intersubjetivas. En esa medida, ¿hasta qué punto tiene sentido seguir hablando aquí, de manera esencialista, de amo y esclavo como tipos humanos llamados por raza, linaje, privilegios de nacimiento y posesión, etc., a mandar u obedecer? Como nos enseña Hegel, lo negativo no posee una esencia fija, depende de su lugar en la relación, y por eso la contradicción entre señores y siervos, la parcialidad de sus actitudes, debe resolverse históricamente en un reconocimiento mutuo ${ }^{37}$. Ahora bien, no cabe pensar en una síntesis dialéctica, en un equilibrio último que anule la conflictividad trágica de la existencia, ni tampoco, por tanto, que elimine toda distinción-aunque sea siempre de carácter contingente- entre gobernantes y gobernados. A lo cual añade Nietzsche otra

${ }^{36}$ Cfr. Manuel Barrios, La voluntad de poder como amor. Barcelona, Serbal, 1990; reed. en Madrid, Arena Libros, 2006, pp. 62-80.

${ }^{37}$ Sobre esta cuestión, remito al capítulo titulado "La voluntad de poder como amor y el problema del reconocimiento", ibid., pp. 81-112.

Araucaria. Revista Iberoamericana de Filosofia, Politica, Humanidades y Relaciones Internacionales, año $23, \mathrm{n}^{\circ} 46$. Primer cuatrimestre de 2021. Pp. 241-271. ISSN 1575-6823 e-ISSN 2340-2199 https://dx.doi.org/10.12795/araucaria.2021.i46.12 
matización nada anecdótica: que la voluntad de quien necesita afirmarse a través de la negación o el sometimiento del otro es, en el fondo, débil y reactiva; que lo que hay que alentar y extender cada vez más es "el impulso originariamente artístico y raro a atribuirse un valor a sí mismo y desde sí mismo", a "pensar bien de sí mismo" (JGB-261). Esto es: donde verdaderamente se prueba la fuerza, es en la capacidad para sostener la diferencia, para tolerar la diversidad de puntos de vista y formas de vida. Nietzsche nunca desatiende las diferencias cualitativas existentes entre una actitud vital afirmativa, que es a lo que él llama "noble", "distinguido" o "aristocrático" (vornehm), y una actitud resentida, decadente, a fin de cuentas más sometida a su propio empobrecimiento anímico que a un agente externo. En la medida en que ambas actitudes pueden convivir dentro de una misma persona, tiene más sentido hablar aquí en términos de fuerzas antes que de individuos. Pero Nietzsche, urgido a elaborar una crítica de esa subjetividad decadente que la modernidad ha heredado de la creencia metafísica en trasmundos - una subjetividad necesitada de valores firmes, absolutos, necesitada de reaseguramiento justo por su debilidad- acaba traicionado por su lenguaje de los tipos humanos superiores y de la raza de los señores de la Tierra, cuando, de hecho, su exploración de una relación ética intersubjetiva sobre la base de los modelos del amor y la amistad, tal como aparecen esbozados en su Zaratustra, rebasa los rigores de esa perspectiva de la dominación.

Todos estos aspectos, que a mi modo de ver son los que procuran rescatar hoy día quienes interpretan en clave positiva el agonismo nietzscheano, estaban apuntados en el citado libro bajo la óptica de la superación del nihilismo y la creación de valores afirmativos en una cultura trágico-dionisíaca. Pero también señalé expresamente lo que allí denominaba "los límites del proyecto políticocultural nietzscheano" 38 , el hecho de que el problema de la liberación de las fuerzas creadoras no recibe una respuesta suficientemente esclarecedora desde el punto de vista cívico, social y político por parte del filósofo. Siguiendo con esta línea de argumentación, concluiré mi propósito de mostrar en el presente artículo, de forma necesariamente muy sintética, qué aspectos del pensamiento nietzscheano me parecen más provechosos para el despliegue de una democracia pluralista, en el sentido del agonismo político, en franca controversia con la utilización que algunos autores afectos a este posicionamiento teórico hacen de formulaciones schmittianas en su redefinición del espacio de lo político. Por último, apuntaré algún reparo a la plena integración de Nietzsche dentro de nuestro rebaño democrático.

\footnotetext{
${ }^{38}$ Ibid., pp. 149-152.
} 


\section{III}

Como se indicó antes, los defensores de un agonismo político cuestionan el modelo de una teoría política liberal basada en el consenso, y no sólo en cuanto su eficacia, sino en cuanto su posibilidad misma, pues no comparten el presupuesto de que haya un espacio neutro de deliberación, plenamente objetivo, que permita una decisión racional ante posturas contrapuestas: siempre intervienen afectos, intereses, asunciones estratégicas, etc., con lo cual ahí donde se concibe el consenso como superación de las diferencias, se hace a costa de silenciar puntos de vista contrarios. En esa línea, estos autores recuerdan consideraciones sobre la violencia subyacente a la pretensión de imponer una verdad absoluta, universal y objetiva, que uno puede encontrar en Nietzsche, pero también en otros pensadores menos inquietantes, como es el caso de Hannah Arendt ${ }^{39}$. La insistencia en el cierre en torno al consenso suele ser vista por los agonistas como síntoma de un acto de exclusión, que limita el alcance del juego democrático. Una democracia verdaderamente pluralista no debería pensar que el objetivo de la política es la supresión del conflicto, sino su potenciación, ya que lo saludable es generar un espacio de discusión que asuma el carácter irreductible de los antagonismos. Hasta aquí son argumentos que resultan atendibles en su buena voluntad de profundización democrática. El problema comienza cuando, en su propósito de politizar la política, de reintroducir el conflicto en el espacio demasiado homogeneizado de la democracia actual, agonistas como pueda ser el caso destacado de Laclau recurren a las ideas de Carl Schmitt, para quien la esencia de lo político radica en la neta distinción entre amigos y enemigos. Las implicaciones son de largo alcance y no meramente anecdóticas por el hecho de que Schmitt sea un teórico de la revolución conservadora, legitimador del nazismo, y Laclau un pensador de la izquierda posmarxista, teórico del populismo. Ambos rechazan el liberalismo y tildan de ineficaces a las democracias parlamentarias por su neutralización de la política. Consideran que el Estado y los poderes fácticos del mercado, preocupados tan sólo de garantizar propiedad privada y libertad personal, no ven sino competidores económicos y oponentes ideológicos coyunturales, sin querer asomarse al trasfondo real que da genuino sentido a la acción política. Ahora bien, ¿qué es lo que se pretende en el fondo con esta vuelta a las esencias? Schmitt lo tiene claro y lo dice sin tapujos: superar el carácter anodino de un parlamento que se limita a la negociación partidista, que no toma verdaderas decisiones y que, por tanto, tampoco cumple su función de representación. Para ello es preciso la identificación del enemigo, que es

${ }^{39}$ Para una lectura que sintoniza a ambos pensadores en esta línea, vid. Dana Villa, "Democratizing the Agon: Nietzsche, Arendt and the Agonistic Tendency in Recent Political Theory", en Alan D. Schrift, Why Nietzsche Still?, Berkeley/Los Angeles, University of California, Press, 2000, pp. 224-246.

Araucaria. Revista Iberoamericana de Filosofia, Política, Humanidades y Relaciones Internacionales, año $23, \mathrm{n}^{\circ} 46$. Primer cuatrimestre de 2021. Pp. 241-271. ISSN 1575-6823 e-ISSN 2340-2199 https://dx.doi.org/10.12795/araucaria.2021.i46.12 
lo que permite a un colectivo constituirse verdaderamente como un cuerpo político y actuar en consecuencia, en busca de su hegemonía ${ }^{40}$. La enemistad es el alma de la política, del mismo modo que el conflicto es la condición natural de la existencia. La política real, no el parloteo intranscendente que sería para Schmitt la actividad parlamentaria, contempla siempre la posibilidad de la guerra como escenario más cierto de su despliegue. Así, afirma Schmitt en su ominoso escrito "El Führer protege el derecho":

En la urgencia extrema es donde el derecho supremo se pone a prueba, y donde se manifiesta el grado más elevado de realización vindicadora de este derecho por parte de un juez. Todo derecho acusa su origen en el derecho a la vida de un pueblo. Toda ley estatal, toda sentencia pronunciada por un juez tienen únicamente de derecho lo que esta fuente deja fluir hacia ella. El resto, lejos de ser derecho, no es más que una "red de normas positivas constrictivas", de la que se burlan los criminales astutos ${ }^{41}$.

Lo que dice aquí Schmitt es bien distinto al agonismo que pretende inspirarse en Nietzsche, donde la identidad de uno no se construye reactivamente a partir de la negación del otro ni aspira a su supresión. Porque éste es el sentido último del planteamiento schmittiano. En una lectura oportunista del Leviathan hobbesiano, Schmitt protesta contra la inanidad del poder del Estado liberal burgués, que habría quedado prendido del engaño que supone la ficción del pacto social, incapaz de reconocer que lo que sigue existiendo no es, a fin de cuentas, sino ese estado natural de guerra de todos contra todos, del que se lucran los astutos discutidores de la norma, y del que hay que salir por la vía más expeditiva, esto es, declarando explícitamente el derecho de un pueblo a la vida, o sea, declarando la guerra al enemigo. Esto es así porque Schmitt concibe a ese colectivo, el pueblo, según el formato de una identidad sustancial, tal como antaño la encarnara el monarca absolutista, mientras que no ve en el parlamentarismo liberal sino una proliferación de opiniones e intereses particulares, dispersos, en eterna competencia, que no pueden ser reconducidos a una única verdad. Su pensamiento sigue apegado a un modelo teológicopolítico donde la soberanía vendría a ejercerse como expresión de una voluntad colectiva homogénea, al modo de la democracia plebiscitaria, o, más descarnadamente, en el acto por excelencia del poder único, incontestable, de

${ }^{40}$ C. Schmitt, El concepto de lo político, Madrid, Alianza, 2009, pp. 58-59: "Enemigo no es, pues, cualquier competidor o adversario. Tampoco es el adversario privado al que se detesta por cuestión de sentimientos o antipatía. Enemigo es sólo un conjunto de hombres que siquiera eventualmente, esto es, de acuerdo con una posibilidad real, se opone combativamente a otro conjunto análogo. Sólo es enemigo el enemigo público, pues todo cuanto hace referencia a un conjunto tal de personas, o en términos más precisos a un pueblo entero, adquiere eo ipso carácter público".

41 Carl Schmitt, "Der Führer schützt das Recht", en Deutsche Juristen-Zeitung, cuaderno 15 (01.08.1934), columnas 945-950. La cita es de la 947; trad. en: Héctor Orestes Aguilar (comp.), Carl Schmitt, teólogo de la política. México, FCE, 2001, p. 116. 
quien decide el estado de excepción, trasunto de la vieja omnipotencia divina. La deslegitimación del espacio de la política moderna opera aquí al servicio de esta recuperación de un poder soberano de decisión arbitraria sobre la vida y la muerte. Con ello, de hecho, Schmitt borra la distinción entre estado de naturaleza y sociedad civil. No sólo regresa así a un escenario premoderno, anterior al pacto que da fin a la guerra de todos contra todos, sino cabalmente a un momento pre-político. En definitiva: Schmitt añora un orden de cosas donde los ciudadanos, con su diversidad de opiniones e intereses, en tanto gobernados, en tanto súbditos, desaparezcan, fundidos en esa comunidad uniforme de pertenencia a la que el gobernante genial, fundador del Estado, impone su dictado.

Pero ésta no es la posición de Nietzsche, ni en lo concerniente a su idea del agonismo ni a la de la presunta continuidad entre orden legal y violencia fundadora. El realismo político de Nietzsche, como el de Hobbes, no se engaña ciertamente respecto al carácter cruel, despiadado, amenazante, del hombre para el hombre en los estadios primitivos de su evolución histórica. Por eso, en La genealogía de la moral, explica las formas más rudimentarias de justicia como prácticas de pura y simple devolución de la deuda, como un hacer pagar al otro con la misma moneda, de manera que en este punto no se rebasaría aún el "estado salvaje y sin ley" (GM-II, 9), en el que se responde al daño infligido con idéntica violencia. Pero también, justo por ese motivo, Nietzsche entiende que la fundación de un estado de derecho supone una neta ruptura respecto a ese estadio previo donde domina la venganza. Este corte abrupto no nace desde luego de la benevolencia, de los buenos sentimientos o de la sociabilidad espontánea de los seres humanos, ni de su acuerdo explícito, sino que es un acto de imposición de la ley. El acuerdo, el atenerse a la norma, la existencia de lo 'justo' y lo ‘injusto', vienen después, “sólo a partir de la instauración de la ley", una vez que "un poder más fuerte busca medios para poner fin (...) al insensato furor del resentimiento", "logrando así a la larga lo contrario de lo que pretende toda venganza, que sólo ve y hace valer el punto de vista del damnificado (...), ejercitándose en llegar a una apreciación cada vez más impersonal de la acción" (GM-II-11). Como añade Nietzsche, esta situación de derecho es en verdad "excepcional" (id.), ella es la que constituye el milagro que restringe la tendencia espontánea del poder a querer más y extenderse sin freno, ella limita la pulsión natural, biológica, y genera derecho ${ }^{42}$. Precisamente por eso, este orden no debe ser totalizador, tal como lo sería, a su juicio, "el

\footnotetext{
${ }^{42}$ Como Nietzsche explica en el epígrafe anterior, a partir del establecimiento de la ley y la justicia, conforme una comunidad crece en poder y conciencia, suaviza su derecho penal, hasta el punto de poder concebir la renuncia a toda reparación del daño: "la medida de su riqueza viene dada por la merma que es capaz de soportar sin padecer por ello". Éste es el caso de la medida de gracia, el perdón, la conmutación de la pena, una especie de superación de si misma de la justicia, un "más allá del derecho" (GM-10 = OC, IV, 496).
} 
modelo comunista de Dühring”. Puede limitar el impulso natural de la vida a la lucha, pero no pretender suprimirlo por entero. Debe entenderse, concluye Nietzsche, como un "instrumento de mediación en la lucha entre diferentes complejos de poder", pero no ir "contra toda lucha en absoluto" (id.). Así, su equilibro siempre es relativo, frágil, susceptible de romperse: "El derecho surge sólo donde hay contratos; pero para que haya contratos, tiene que existir un cierto equilibrio de poder. Si falta este equilibrio, si chocan dos cantidades de poder demasiado diferentes, la más fuerte se extiende hacia la más débil para continuar debilitándola hasta que finalmente se produce el sometimiento, la adaptación, la integración, la asimilación; con el final, pues, de que los dos se han convertido en uno"43. La consecuencia es clara para Nietzsche: hay que aspirar a "cierto equilibrio" entre poderes, que mitigue la violencia, para que no suceda lo que tuvo que suceder entre melos y atenienses:

\begin{abstract}
Tucídides (...) ha dicho lo que debe por fuerza suceder tan pronto como la polis deja de existir: despedazamiento mutuo y desencadenamiento de todas las pasiones. Aquí se manifiesta la naturaleza humana en estado puro, mientras que la polis la mantiene a raya (...) En el Estado domina el derecho, no la venganza, todos quedan protegidos de la injusticia de los otros y la rivalidad no posee un carácter nocivo ${ }^{44}$.
\end{abstract}

La distancia entre el agonismo nietzscheano y el antagonismo schmittiano es aquí decisiva: el primero busca un despliegue pluralista de las fuerzas a partir de un equilibrio básico de poderes, sin el cual la rivalidad no puede ser saludable ni productiva; mientras que el segundo busca exacerbar el conflicto, pero sólo para resolverlo a la postre de manera terminante. Ésta es también, me temo, la tentación populista, secretamente deseosa de la victoria final de "los nuestros" frente al enemigo. Ya hemos visto en qué medida la aspiración a hacer política de otro modo se convierte en Schmitt en la peligrosa pretensión de hacer otra cosa que la política, o sea, la guerra, puro ejercicio del poder más allá de toda norma positiva establecida. De ahí que el jurista alemán califique despectivamente de juego o divertimento insulso a la política democrática real. En cambio, en la concepción nietzscheana del agonismo, la aceptación de las reglas es condición necesaria para ese "cierto equilibrio" que da al enfrentamiento la garantía de su excelencia. Porque es juego, i.e., recreación cultural que mitiga la violencia guerrera del origen y la encauza positivamente, es por lo que todo certamen, incluido el político, resulta enriquecedor. Este autocontrol no es debilitante, sino expresión de una mayor fuerza, en tanto posibilita la generación de diferencias y las soporta. En este sentido, incluso el

${ }^{43} \mathrm{NF}, \mathrm{I} 5$ [82] = FP, IV, 170.

${ }^{44}$ FP, II, 12 [21], p. 213. Tomo la conexión entre estas dos secuencias de ideas nietzscheanas del artículo de Diego Sánchez Meca, "Un análisis genealógico de la justicia”, en Atlantis, revista de pensamiento y educación, 1 (2011), pp. 17-29. Vid. en especial pp. 22-28.

Araucaria. Revista Iberoamericana de Filosofia, Politica, Humanidades y Relaciones Internacionales, año $23, \mathrm{n}^{\circ} 46$. Primer cuatrimestre de 2021. Pp. 241-271. ISSN 1575-6823 e-ISSN 2340-2199 https://dx.doi.org/10.12795/araucaria.2021.i46.12 
amigo es para Nietzsche, como dice en Zaratustra, adversario, estímulo para la autosuperación. Se trata, en definitiva, de rasgos que orientan su pensamiento hacia un pluralismo - $\mathrm{O}$, como él lo denomina, un perspectivismo- contrario a toda ambición de dictar de una vez por todas el sentido de lo real, de dar voz a un único genio que se sienta en posesión de la verdad. La muerte de Dios significa precisamente que no hay nunca una interpretación concluyente, que el hueco que deja ese fundamento ausente nunca puede ser colmado del todo, ni por la voz del soberano añorado por Schmitt ni por la del pueblo desvalido de la razón populista ${ }^{45}$.

Ahora bien, ¿por qué, entonces, este tipo de planteamientos no conduce a Nietzsche a una mayor sintonía con la democracia? Podría decirse que Nietzsche desconfía de esa paz perpetua del consenso, tal como la formula una modernidad política que idealiza los supuestos del pacto social, tratando de darles un fundamento universalista de naturaleza objetiva. Uno de los referentes inequívocos de su crítica a este respecto es el pensamiento de Rousseau, del que deplora su optimismo ingenuo, su sentimentalismo y su igualitarismo ${ }^{46}$. La condición de sujetos libres e iguales nace del contrato social, no al revés, y esta formalidad jurídica no tendría por qué convertirse en excusa para una igualdad que acabe siendo uniformidad y nivelación, generación de masa y no de individuos. Lo que Nietzsche combate es esa abstracción igualitarista que rechaza las diferencias, como si no existieran, con lo que practica una idealización, un ocultamiento de la realidad, no exentos de violencia. Su noción de justicia, como ha señalado oportunamente Diego Sánchez Meca, no equivale sin más a igualdad en este sentido, sino a dar a cada uno lo que merece. De ahí sus constantes alusiones polémicas a la "igualdad de derechos". El reparo no reside tanto en el punto de partida como en el resultado de esta normalización. De hecho, en sus escritos del período intermedio, Nietzsche muestra a menudo una actitud mucho más receptiva ante las posibilidades de crear una cultura superior que se abren en el mundo moderno, como cuando comenta:

El comercio y la industria, el intercambio de libros y cartas, la participación común en toda la alta cultura, el rápido cambio de lugar y país, la actual vida nómada de todos los que no poseen tierras, -todas estas circunstancias traen necesariamente consigo un debilitamiento de todas las naciones y, al final, su destrucción, por lo menos las europeas; de modo que, a partir de todas ellas, tras continuos cruces, nacerá una raza mixta, la del hombre europe $\mathrm{o}^{47}$.

${ }^{45}$ Cfr. Ernesto Laclau, La razón populista (Buenos Aires-México, FCE, 2005), una obra menos incisiva que la escrita con Chantal Mouffe, Hegemonía y estrategia socialista (México, Siglo XXI, 1987). En general, Mouffe marca mejor que Laclau las distancias frente a Schmit. Vid. al respecto Simon Critchley y Oliver Marchart, Laclau: A Critical Reader. London, Routledge, 2004.

${ }^{46}$ Vid. Keith Ansell-Pearson, Nietzsche Contra Rousseau: a Study of Nietzche's Moral Political Thought. Cambridge, Cambridge University Press, 1996.

47 MA, I, 475 (OC III, 239).

Araucaria. Revista Iberoamericana de Filosofí, Política, Humanidades y Relaciones Internacionales, año $23, \mathrm{n}^{\circ} 46$. Primer cuatrimestre de 2021. Pp. 241-271. ISSN 1575-6823 e-ISSN 2340-2199 https://dx.doi.org/10.12795/araucaria.2021.i46.12 
La mezcolanza de razas, celebrada por este "buen europeo" contra todo prejuicio etnicista, lo es también de valoraciones y concepciones del mundo, y su resultado - una actitud más pluralista y escéptica ante las cosas- acompaña al devenir democrático de Europa. Sin embargo, por más que reconozca estos indicios positivos de cultura superior en la modernidad, Nietzsche detecta también signos preocupantes de contracorrientes, así por ejemplo la de "un nacionalismo artificioso", "tan peligroso como antes lo fue el artificioso catolicismo", por cuanto "no es el interés de la mayoría (de cada pueblo), como gusta decir, lo que le empuja, sino ante todo el interés de determinadas dinastías reinantes y luego el de determinadas clases comerciales y sociales" (idem). Le irrita comprobar cómo las apelaciones a una presunta naturaleza humana se instrumentan ideológicamente al servicio de una moral utilitaria que predica libertad para todos, pero impide una genuina emancipación del individuo. La sospecha de esta continuidad con los elementos residuales de un cristianismo agonizante y artificioso lleva al filósofo, en coherencia con su crítica de la metafísica platonizante y la manía idealista de trasmundos, a condenar de forma cada vez más severa "ideas modernas" tales como las de la bondad natural del hombre, la moral de la compasión o el igualitarismo. Las ve como falsos ídolos que restauran la necesidad de valores absolutos. En ese sentido, movimientos como los del anarquismo y el socialismo de su tiempo son para él herederos de la moral cristiana: siguen calumniando el mundo (la sociedad) al atribuir a una culpa universal su propio malestar, reaccionan al sufrimiento con espíritu de venganza, y este resentimiento los lleva a ambicionar una plenitud de poder político, que en principio reclama "tanto Estado como sea posible" -simplemente para someter a los individuos, para aniquilarlos como tales al convertirlos "en un órgano de la comunidad, conforme a su fin"- pero que al final acaba realizando "tan poco Estado como sea posible", esto es, acaba generando una dinámica puramente desintegradora del orden social. Nietzsche recela profundamente de este socialismo revolucionario (lo que luego vendría a llamarse comunismo), en el que aprecia tendencias totalitarias y medios violentos de actuación, de linaje rousseauniano y talante contrario al genuino "espíritu de la Ilustración y de la evolución progresiva" (MA-463). Por eso, lo que concluye a este respecto en Humano, demasiado humano es que "hacen falta, no nuevos y violentos repartos, sino paulatinas transformaciones de la mentalidad: la justicia debe aumentar en todos, el instinto de la violencia debe debilitarse" (MA-452).

Desde luego, Nietzsche no es un pensador reaccionario: sabe que "no es posible ninguna involución, ninguna vuelta atrás en cualquier sentido y grado" (GD-Streifzuege, 43). No aspira, por consiguiente, a volver a un estadio previo al de la modernidad. Es consciente de que, con la desaparición de la fe en la autoridad absoluta, en la verdad definitiva, una subordinación del tipo de la 
que practicó el despotismo en el pasado también tiene que desaparecer; y de que, en esperables situaciones de mayor libertad, los individuos sólo han de aceptar someterse por motivos pragmáticos, "como consecuencia de un pacto recíproco, con todas las reservas del propio interés" (MA, I, 475). Pero esto es lo que no ve asegurado en la sociedad de masas que se va configurando dentro del espacio europeo. La promesa de un final de la historia redentor arbitrada por los distintos movimientos ideológicos de su época le parece un residuo metafísicoreligioso, que sigue tiene teniendo como uno de sus efectos más indeseables la conversión del individuo en una pieza prescindible del engranaje. Desconfía de este Estado nivelador, del sentido mediocre de la vida que se desprende del carácter demagógico de todos los partidos políticos, y su rechazo se va volviendo más visceral, hasta proponer como revulsivo esa casta de señores que sepan replicar a la moral de rebaño con una moral de la autosuperación. Éste es el escenario de la "gran política".

Teóricos del agonismo en Nietzsche como Connolly, Honig o Vanessa Lemm aportan argumentos de interés para defender la posibilidad de ver conjugados en su pensamiento aristocratismo y democracia: Nietzsche no habla de una "clase aristocrática", sino de una "sociedad aristocrática" (JGB, 257); su mención de la palabra "esclavitud" aplicada al hombre actual es metafórica, queriendo referirse con ello al trabajo asalariado, no a un sometimiento despótico; habla de los señores del futuro como "tiranos", pero se refiere sobre todo al modelo platónico de los filósofos gobernantes, a "tiranos del espíritu" 48 ; la relación entre el noble y el esclavo no es una relación jerárquica del tipo de la que se da entre gobernantes y gobernados, sino una diferencia en los valores que cada uno de ellos tiene por más estimables... Es verdad que lo que hace al noble en Nietzsche no es en última instancia ni la pertenencia a una raza ni a un estamento social privilegiado, sino la opción por ser creador de valores que afirmen su existencia y que no condenen de forma perversa y fanática a quienes piensan distinto; que le sitúen en condiciones de hacer valer su individualidad sin someterse a principio homogeneizador alguno. Esto puede ser sugerente para pensar la identidad de la colectividad social de manera no esencialista, para dejar siempre abierto un hueco, de modo que el nosotros acoja lo ajeno y extranjero, para que cualquiera pueda entrar en la pugna por ocupar un espacio dentro de la comunidad política. Pero éste no es, en estricto sentido, el planteamiento de Nietzsche; o, al menos, no es todo su planteamiento. Lo que él sugiere más bien en sus escritos de madurez es una difícil, extraña convivencia entre una masa de trabajadores asalariados, moderadamente felices en la zona templada de la vida, con las necesidades básicas cubiertas, capaces de soportar el trabajo pesado, y unos individuos de excepción liberados de esa carga y dedicados por encima de todo al cultivo de

\footnotetext{
${ }^{48}$ Cfr. MA, I, 261.
} 
la esfera superior del espíritu -, ciertamente no enfangados en la política, no preocupados por ejercer esa clase de poder ni de dominación ${ }^{49}$, sino entregados a la exploración de nuevas formas de existencia, que luego podrían llegar a proponerse como nuevos valores al conjunto de la sociedad. Nietzsche concibe expresamente a este tipo de individuos señalados como aquellos que soportan la mayor exigencia de autodominio, sacrificio, tolerancia y respeto ${ }^{50}$; matiza -a veces- que su señorío no consistiría en la subyugación de los demás, sino que sería fruto de una aceptación de su excelencia por parte de éstos, respecto a quienes mantendrían una separación espacial y política. Pero justamente esta separación y la consiguiente instrumentalización de unos individuos al servicio de otros ${ }^{51}$ es lo que no acaba de cuadrar con la interpretación de quienes proponen una plena concordancia de Nietzsche con la democracia. Al tratar de preservar el valor del tipo noble dentro de una sociedad que tiende al igualitarismo, Nietzsche se enreda en formulaciones ambiguas, cuando no contradictorias, que dan un sesgo inquietante a su radicalismo aristocrático ${ }^{52}$.

Con todo, es cierto que a veces despunta en sus textos otra aurora. Meditando sobre el problema de cómo integrar el pathos de la distancia en la cultura del presente, afirma que en todas las culturas más elevadas pueden aparecer intentos de mediación entre una moral de señores y una moral de esclavos, "incluso en el mismo hombre, dentro de una sola alma" (JGB, 260). ¿No podría ser este agonismo interno más profundo, más sutil, más distanciador en el fondo que el que aún mantiene una divisoria demasiado metafísica al formularse como una distancia entre hombre y hombre? ¿No conviven acaso lo alto y lo bajo, lo noble y lo vil en cada uno de nosotros, como ocasión permanente de ascenso y decadencia vital? Nietzsche parece percibir esta posibilidad en el arranque de la novena sección de Más allá del Bien y del Mal, titulada “¿qué es aristocrático?”. Allí distingue dos momentos en el proceso histórico de desenvolvimiento de ese espíritu de distinción. En el primero, la existencia de una sociedad aristocrática habría sido condición inexcusable para el surgimiento del pathos de la distancia (y es lo que repite provocadoramente

${ }^{49}$ Cfr. v.g. NF-1887 9 [153]. Vid. también JGB, 242.

50 Vid. v.g. GD-Streifzuege- 49.

51 JGB-258: "Lo esencial en una aristocracia buena y sana es que no se sienta a sí misma como función (sea de la realeza, sea de la comunidad), sino como su sentido y suprema justificación, — que acepte con buena conciencia el sacrificio de un sinnúmero de personas que por causa de ella tienen que ser oprimidas (herabdrücken) y reducidas a la condición de hombres incompletos, esclavos, instrumentos".

${ }^{52} \mathrm{La}$ igualdad (Gleichheit) formal ante la ley -idea coherente con lo dicho sobre la regla de juego común a todo competidor en un certamen- no tiene por qué implicar necesariamente indiferencia de valor (Gleichgültigkeit) entre los individuos. Esta falta de distingos en Nietzsche complica la lectura democratizante de su aristocratismo. Más aún ahí donde él protesta expresamente contra la extensión de derechos a determinados sectores de población (mujeres, obreros). Cfr. v.g. el aforismo "La cuestión obrera" en GD-Streifzuege-40. Para una visión crítica de este aristocratismo, vid. Keith Ansell-Pearson, An Introduction to Nietzsche as Political Thinker. Cambridge, Cambridge University Press, 1994.

Araucaria. Revista Iberoamericana de Filosofia, Política, Humanidades y Relaciones Internacionales, año $23, \mathrm{n}^{\circ} 46$. Primer cuatrimestre de 2021. Pp. 241-271. ISSN 1575-6823 e-ISSN 2340-2199 https://dx.doi.org/10.12795/araucaria.2021.146.12 
a lo largo de toda esa sección). Pero a esa consideración añade Nietzsche, en un matiz significativo, lo que cabría entender como un segundo momento, donde lo requerido como condición no sería ya aquel modelo caduco de ordenamiento social, sino lo ganado mediante él, esto es, el propio pathos de la distancia. Así que ahora, sin dicho pathos de la distancia "no podría surgir tampoco en modo alguno aquel otro pathos misterioso, aquel deseo de ampliar constantemente la distancia dentro del alma misma, la elaboración de estados más elevados, más raros, más lejanos, más amplios, más abarcadores, en una palabra, justamente la elevación del tipo 'hombre', la continua 'auto-superación del hombre'" (JGB257). Esta otra dimensión más misteriosa no tiene que ver con las relaciones convencionales de poder, es coherente con su desmontaje genealógico de las creaciones humanas como algo dado, y podría haber invitado a Nietzsche a explorar su extensión a todas las almas, porque resulta ser cabalmente dentro de esa multiplicidad pulsional que es el yo donde se libra, según sus propios planteamientos, la auténtica pugna por la excelencia, la cual nace de la intensificación de la tensión interna, como en la musculatura del atleta, del juego de las diferencias y de la capacidad de incorporarlas ${ }^{53}$. Eso que Nietzsche experimentó en su propia piel, el ser a la vez decadencia e inicio, el aprender a vencerse a sí mismo, es lo que no acaba de trasladar con consistencia a su pensamiento político.

Toda su reflexión sobre las dinámicas de la décadence resulta por eso tan apasionante, tan compleja y cargada de ambigüedades; porque Nietzsche advierte, por una parte, que la cultura es trabajo de suavización de los instintos, que el ennoblecimiento no deja de ser producto de un cierto decaimiento fisiológico -los nobles que imagina no serían, en el fondo, sino las flores más exóticas entre los décadents del mundo moderno, ésos que pueblan sus anotaciones tardías sobre el París finisecular-pero, por otra parte, teme que esta mitigación sea ocasión de debilitamiento reactivo, de empobrecimiento vital. Y si en su vindicación del filósofo-artista asiente a esta compleja condición experimental de la vida moderna, a esa rara simbiosis de primavera y otoño, deduciendo de ahí -en coherencia con el pensamiento de la voluntad de poder como derroche y donación- que la actitud del señor es la menos violenta, la más entregada, esto es, la de una especie de asceta espiritual que se aparta del mundanal ruido de todo ese circuito aburguesado de trabajo, comercio y consumo, en cambio, en sus proclamas sobre la gran política resurge el presupuesto de que es precisa una neta separación entre señores y siervos. Así, en este punto, la posibilidad de pensar hasta el fondo una articulación de democracia y cultura aristocrática queda coagulada en su filosofía.

${ }^{53}$ Paul van Tongeren, Die Moral von Nietzsches Moralkritik. Studie zu "Jenseits von Gut und Böse”. Bonn, Bouvier, 1989, 165-171. 


\section{$* * *$}

Una última consideración, acaso algo intempestiva: ¿Hasta qué punto merece la pena intentar democratizar a Nietzsche, forzando la literalidad de sus textos con una lectura que responda a nuestras expectativas? Ya se señaló al principio: Nietzsche busca lectores pacientes, que sepan resistir al impulso de reaccionar de inmediato ante la sacudida de sus más firmes convicciones, que no traten de hallar refugio en lo acostumbrado, que aprendan a ver su mundo de otro modo: ¿Es la democracia la forma política más deseable? ¿Hay espacio para la verdadera excelencia en nuestro estilo de vida? Puede que Nietzsche no haya querido sino provocarnos con unas respuestas tan diferentes a las nuestras, que por fuerza tengan que dejar abiertos los interrogantes. Éste es su desafío. 


\section{Referencias bibliográficas:}

Acampora, Christa D. "The Contest between Nietzsche and Homer: Revaluing the Homeric Question", en N. Martin (ed.), Nietzsche and the German Tradition, Oxford/N. York, Lang, 2003: 83-109.

Acampora, Christa D., Demos Agonistes Redux: Reflections on the Streit of Political Agonism, Nietzsche-Studien 32 (2003): 374-390.

Aguilar, Héctor Orestes (comp.), Carl Schmitt, teólogo de la politica. México, FCE, 2001.

Albert, Henri, "Nietzsche contre les Barbares", en L'Opinion, 31.1.1915, pp. 60-62.

Ansell-Pearson, Keith, Nietzsche Contra Rousseau: a Study of Nietzche's Moral Political Thought. Cambridge, Cambridge University Press, 1996.

Ansell-Pearson, Keith, An Introduction to Nietzsche as Political Thinker. Cambridge, Cambridge University Press, 1994.

Aschheim, Steven, The Nietzsche Legacy in Germany, 1890-1990. Berkeley, University of California Press, 1992.

Baeumler, Alfred, Nietzsche der Philosoph und der Politiker, Leipzig, Reclam, 1931.

Barrios, Manuel, La voluntad de poder como amor. Madrid, Arena Libros, 2006.

Bataille, Georges, "Nietzsche et les fascistes", en Acéphale, 2, 21 de enero de 1937, pp. 3-13.

Brandes, Georg, "Aristokratischer Radikalismus. Eine Abhandlung über Friedrich Nietzsche", en Deutsche Rundschau 63 (1890), pp. 52-89.

Campioni, Giuliano, Sulla strada di Nietzsche. Pisa, ETS, 1992; Deleuze, Deleuze, Nietzsche et la philosophie, París, PUF, 1962.

Cavell, Stanley, Conditions Handsome and Unhandsome: The Constitution of Emersonian Perfectionism. University of Chicago Press, 1990.

Connolly, William E., Identity|Difference: Democratic Negotiations of Political

Paradox. Minneapolis, University of Minnesota Press, 2002.

Connolly, William E., Pluralism. Durham, Duke University Press. 2005.

Conway, Daniel W., Nietzsche and the Political. Londres, Routledge, 1997.

Critchley, Simon; Marchart, Oliver, Laclau: A Critical Reader. London, Routledge, 2004.

Detwiler, Bruce, Nietzsche and the Politics of Aristocratic Radicalism, Chicago, University of Chicago Press, 1990.

Derrida, Jacques, L'écriture et la différence. París: Seuil, 1967

D’Iorio, Paolo, Le voyage de Nietzsche à Sorrente. Gènese de la philosphie de l'esprit libre. París, CNRS, 2012. 
Elberfeld, Rolf, "Durchbruch zum Plural. Der Begriff der Kulturen bei Nietzsche", en Nietzsche-Studien 37, 2008, pp. 115-142.

Ferraris, Maurizio, ed., Nietzsche. Bari, Laterza, 1999.

Fornari, Maria Cristina, La morale evolutiva del gregge. Nietzsche legge Spencer e Mill, Pisa, ETS, 2006.

Forth, Christopher E., Zarathustra in Paris. The Nietzsche Vogue in France, 1891-1918. DeKalb: Northern Illinois University Press, 2001.

Foucault, Michel, "Nietzsche, Freud, Marx", en Nietzsche. Cahiérs du Royaumont, Les Éditions du Minuit, 1964, pp. 183-192; «Nietzsche, la généalogie, l'histoire», en AA.VV., Hommage à Jean Hyppolite, París, P.U.F., 1971, pp. 145-172.

Hatab, Lawrence J., A Nietzschean Defense of Democracy: An Experiment in Posmodern Politics, Chicago, Open Court, 1995.

Hatab, Lawrence J., "Prospects for a Democratic Agon: Why We Can Still Be Nietzscheans", Journal of Nietzsche Studies 24 (2002): 132-147.

Honig, Bonnie, Political Theory and the Displacement of Politics, Ithaca/NY, Cornell University Press, 1993.

Jünger, Ernst, Der Arbeiter. Herrschaft und Gestalt. Hamburg, Hanseatische Verlagsanstalt, 1932.

Krummel, Richard F., Nietzsche und der deutsche Geist. 4 vols. Berlín, Walter de Gruyter, 1974.

Laclau, Ernesto, La razón populista. Buenos Aires-México, FCE, 2005.

Laclau, E.; Mouffe, Chantal, Hegemonía y estrategia socialista, México, Siglo XXI, 1987.

Lemm, Vanessa, Nietzsche y el pensamiento político contemporáneo, Chile, FCE, 2012.

Losurdo, Domenico, Nietzsche, il ribelle aristocrático. Turín, Boringhieri, 2002.

Lukács, Gyorg, Die Zerstörung der Vernunft. Der Weg des Irrationalismus von Schelling zu Hitler, Berlín, Aufbau, 1954.

Lyotard, Jean-François, "Notes sur le retour et le kapital", en Nietzsche aujourd'hui? 10-18. Vol. 1, París, Publications du Centre culturel internationel de Cerisy-la-Salle, 1973, pp. 141-157.

Mann, Thomas, Betrachtungen eines Unpolitischen. Berlín, Fischer, 1918.

Mouffe, Chantal, The Return of the Political. Londres-New York, Verso, 1993.

Nussbaum, Martha, "Is Nietzsche a Political Thinker?", en International Journal of Philosophical Studies, 5 (1997), pp. 1-13.

Ottmann, Hennig, Philosophie und politik bei Nietzsche. Berlín, Gruyter, 1978.

Redhead ,Mark; Connolly, William,"Nietzsche and Liberal Democracy: a Relationship of Antagonistic Indebtedness?" The Journal of Political Philosophy, vol. 5, no. 2 (1997), pp. 183-193. 
Schmitt, Carl, El concepto de lo político, Madrid, Alianza, 2009.

Sánchez Meca, Diego, Nietzsche: la experiencia dionisíaca del mundo, Madrid, Tecnos, 2005.

Sánchez Meca, Diego, "Un análisis genealógico de la justicia”, en Atlantis, revista de pensamiento y educación, 1 (2011), pp. 17-29.

Schrift, Alan D. «Le nietzschéisme comme épistemologie. La réception française de Nietzsche dans le moment philosophique des années 1960» en Patrice Maniglier (ed.), Le moment philosophique des années 1960 en France. París, PUF, 2011, pp. 95-109.

Siemens, Herman, "Agonal Communities of Taste: Law and Community in Nietzsche's Philosophie of Transvalutation", Journal of Nietzsche Studies 24 (2002): 83-112.

Siemens, H; Roodt, H. Vasti (eds.), Nietzsche, Power, and Politics: Rethinking Nietzsche's Legacy for Political Thought, Berlín, De Gruyter, 2008.

Thiele, Leslie Paul, "The Agony of Politics: The Nietzschean Roots of Foucault's Thought", en American Political Science Review 84, 3 (1990): 907-925.

Van Tongeren, Paul, Die Moral von Nietzsches Moralkritik. Studie zu "Jenseits von Gut und Böse”. Bonn, Bouvier, 1989.

Vattimo, Gianni, Il soggetto e la maschera. Nietzsche e il problema della liberazione. Milán, Bompiani, 1974

Vattimo, Gianni, Le avventure della differenza, Milán, Garzanti, 1980.

Villa, Dana, "Democratizing the Agon: Nietzsche, Arendt and the Agonistic Tendency in Recent Political Theory", en: Alan D. Schrift, Why Nietzsche Still?, Berkeley-Los Angeles, University of California, Press, 2000, pp. 224-246.

Nietzsches Kritische Gesamtausgabe Werke und Briefe, a cargo de G. Colli y M. Montinari (KGWB). Berlín/New York, de Gruyter 1967ss. 
